\title{
CONSENT TO SEARCH AND SEIZE: EVALUATING AN INNOVATIVE YOUTH FIREARM SUPPRESSION PROGRAM ${ }^{*}$
}

\author{
RICHARD ROSENFELD** AND SCOTT H. DECKER ${ }^{* * *}$
}

\begin{abstract}
Lt. Joseph Richardson . . recalls attending a meeting in late 1993 at which a woman complained about a house where children played with guns while the mother was away. When police arrived, the children ran into the house. "There was nothing we could do," said Richardson, now [a district captain]. "There was no legal way to get in, and there wasn't enough information to obtain a search warrant." The woman at the meeting then asked a single question that changed everything. "Why don't you just knock on the door and ask that mother if you can search the house?" Richardson realized the woman was right. "I could think of no logical reason why I couldn't ask to search," he recalls. Thus was born the consent-to-search program.
\end{abstract}

\section{INTRODUCTION}

With the increase in youth firearm violence in recent years, policymakers have scrambled to develop feasible and effective responses. Over the past decade, officials have initiated numerous local-level interventions, including gun buy-back programs, targeted weapon sweeps, increased scrutiny of gun dealers, and various forms of "gun education." Unfortunately, however, there have been few evaluations of these interventions. One such local initiative is the St. Louis Metropolitan Police Department's Firearm Suppression Program ("FSP"), a program that seeks parental consent to search for and seize guns from juveniles. The program has received extensive national attention for its creative, yet controversial approach to reducing youth firearm violence. This paper describes the FSP, considers criticisms of its methods and purposes, and sets forth a plan for evaluating the operation and outcome of this and similar programs. The paper begins by placing the issues for evaluation in the context of recent increases in the level of youth firearm violence.

Copyright $\odot 1996$ by Law and Contemporary Problems

* This research was supported by a grant from the National Institute of Justice (95-IJ-CX-0067) Points of view are those of the authors, and do not necessarily represent the position of the United States Department of Justice. An earlier draft of this paper was presented at the conference "Prospects for Disarming Urban Youth," sponsored by the Harry Frank Guggenheim Foundation, Santa Fe, New Mexico, September 7-9, 1995.

** Professor of Criminology and Criminal Justice, Department of Criminology and Criminal Justice, University of Missouri-St. Louis.

*** Professor of Criminology and Criminal Justice, Department of Criminology and Criminal Justice, University of Missouri-St. Louis.

1. Bill Bryan. Soft Sell of Searches Nets Police 3,900 Guns, ST. Louis Post-DisPatCH, Apr. 10, 1995 , at 13A. 


\section{II \\ YOUTH GUN VIOLENCE}

St. Louis is a particularly appropriate site for research on criminal violence because it has one of the highest rates of gun violence and homicide in the country. The city's homicide rate ranked among the top three of all large cities in 1991, 1992, and 1993. The number of homicides in St. Louis fell during the first half of the 1980s and then began to rise toward the end of that decade. As Figures $1 \mathrm{a}$ and $1 \mathrm{~b}$ illustrate, nearly all of the increase occurred in homicides committed with firearms. ${ }^{2}$

In addition, the age of homicide victims and offenders shifted substantially. As shown in Table 1, the percentage of victims under the age of eighteen grew from under seven percent in the early 1980 s to over eleven percent ten years later. The percentage of juvenile offenders also increased substantially, more than tripling from 4.9 percent in the early 1980 s, to 15.1 percent in the early 1990s. Table 2 shows that juveniles contributed disproportionately to the increase in the number of homicides, accounting for twenty-two percent of the increase in homicide victims between 1988 and 1992 and for thirty percent of the increase in offenders during the same period.

TABLE 1

St. Louis Homicide Victims AND SUSPECTS By Age, 1980-1992 (PERCENTS)

\begin{tabular}{lrrrr}
\hline & \multicolumn{2}{c}{$1980-82$} & \multicolumn{2}{c}{$1990-92$} \\
& Victims & Suspects & Victims & Suspects \\
\hline Under 18 & 6.6 & 4.9 & 11.6 & 15.1 \\
$18-24$ & 29.0 & 37.4 & 31.2 & 42.6 \\
$25-34$ & 32.4 & 37.9 & 28.4 & 26.8 \\
$35-54$ & 21.0 & 15.9 & 20.8 & 12.8 \\
Over 54 & 11.0 & 3.8 & 8.0 & 2.7 \\
Total & 100.0 & 99.9 & 100.0 & 100.0 \\
$\quad(\mathrm{~N})$ & $(654)$ & $(572)$ & $(648)$ & $(523)$ \\
\hline
\end{tabular}

Source: St. Louis Homicide Project

2. The data reported for St. Louis in the text, figures, and tables are from the St. Louis Homicide Project. SCOTT H. DECKER ET AL., ST. LOUIS HOMICIDE PROJECT: LOCAL. RESPONSES TO A NATIONAL PROBLEM (1990). 


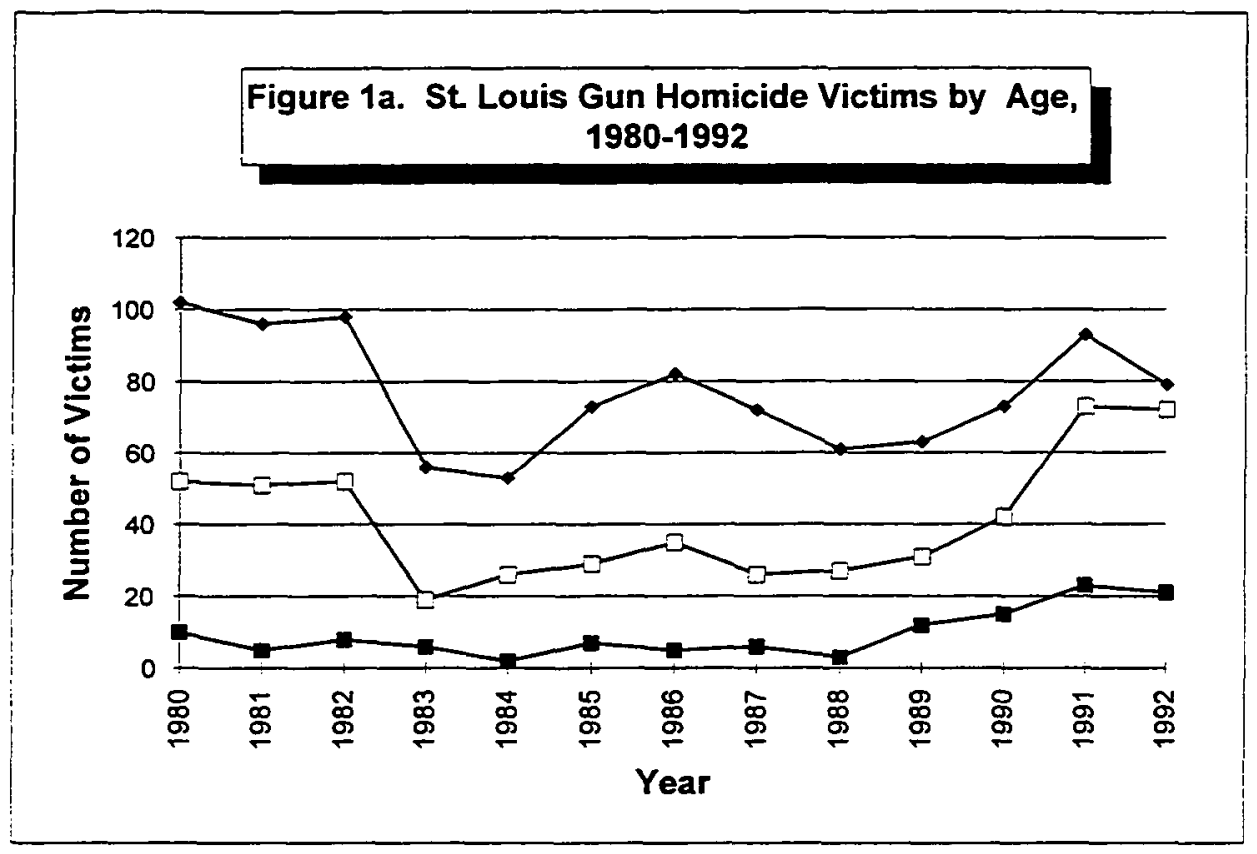

Figure 1b. St. Louis Non-Gun Homicide Victims by Age, 1980-1992

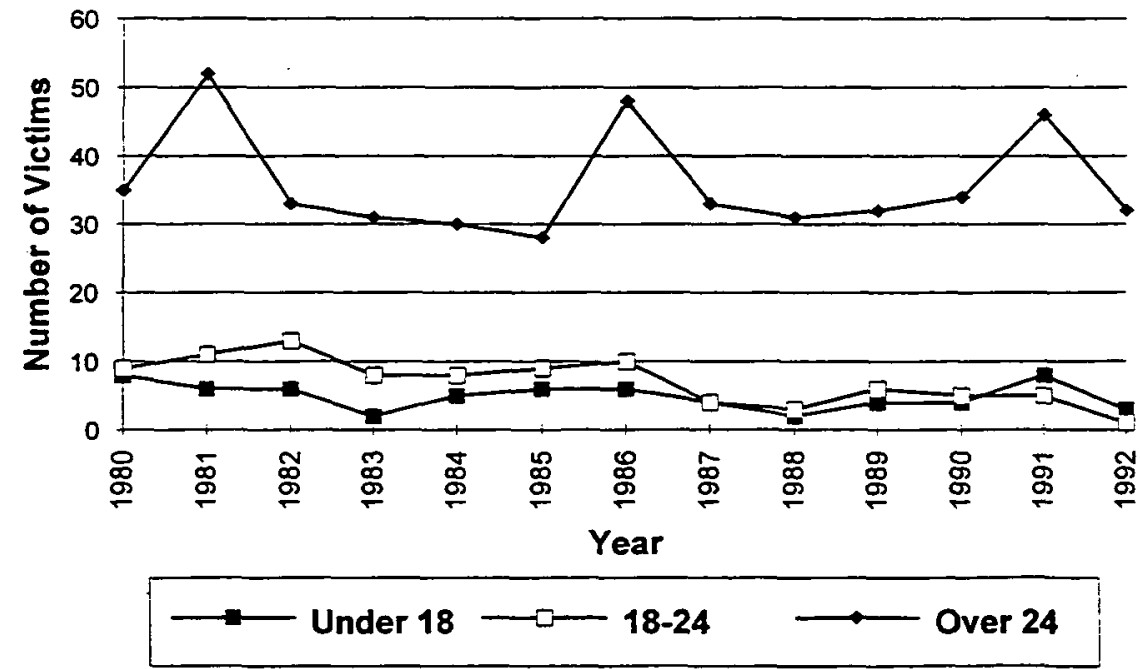




\section{TABLE 2}

INCREASE IN JuVENILE AND AdULt Homicides IN St. LOUIS, 1988-1992

\begin{tabular}{lrrrrrrrr}
\hline & \multicolumn{2}{c}{ Victims } & \multicolumn{7}{c}{ Suspects } \\
& 1988 & 1992 & Diff. & \multicolumn{1}{c}{$\%$} & 1988 & 1992 & Diff. & $\%$ \\
\hline Juvenile & 5 & 25 & 20 & 22 & 12 & 28 & 16 & 30 \\
Adult & 125 & 194 & 69 & 78 & 105 & 142 & 37 & 70 \\
\multicolumn{1}{c}{ Total } & 130 & 219 & 89 & 100 & 117 & 170 & 53 & 100 \\
\hline
\end{tabular}

Source: St. Louis Homicide Project

Figure 2 offers a vivid picture of the disparate risk of death by homicide facing young black males in St. Louis. During the early 1990s, the homicide rate for black males between the ages of fifteen and nineteen was more than five times higher than the city's overall homicide rate. The rate for twenty- to twenty-four-year-old black males was almost twice that of the younger age group-an astounding 627 homicides for every 100,000 persons. ${ }^{3}$

Almost without exception, as Figure 3 illustrates, homicides involving young black males also involve firearms. In the early 1990s, ninety-eight percent of black male homicide victims between fifteen and twenty-four years of age were killed with a firearm, and eighty-eight percent of black male victims between the ages of ten and fourteen were killed with firearms. By comparison, seventy-four percent of black male victims over the age of twenty-four were killed with a gun. These figures demonstrate that the youth homicide problem in St. Louis, as in other racially diverse cities, is concentrated disproportionately among AfricanAmerican youths, and is largely a gun homicide problem.

3. Given the striking magnitude of these figures, a comment on their calculation is warranted. The rates are based on the average of the annual number of homicides occurring between 1990 and 1992. For black males between 15- and 19-years-old, 92 homicides occurred over the three-year period, yielding a three-year average of 30.67 homicides per year. The 1990 census counted 8,276 black males in this age group. The group's yearly average homicide rate for the period therefore equals 370 per 100,000 population $((30.67 / 8,276) \times 100,000)$. Among 20 - to 24 year-old black males, 118 homicides were committed over the same period, for a three-year average of 39.33 homicides. This group numbered 6,275 in the 1990 census, yielding an average yearly homicide rate of 627 per 100,000 population $((39.33 / 6,275) \times 100,000)$. 
Figure 2. Age, Race, and Sex-Specific Homicide Rates in St. Louis, 1990-1992 (Three-Year Average)

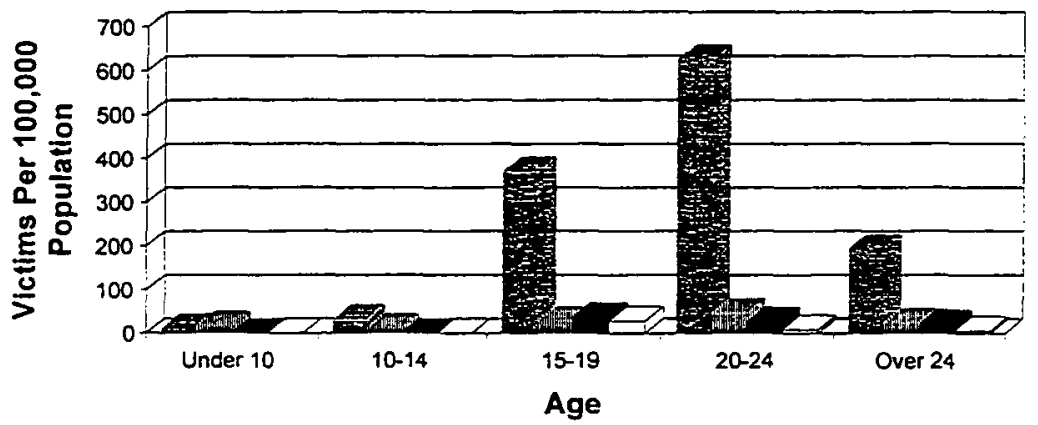

BLACK MALES BLACK FEMALES $\square$ WHITE MALES $\square$ WHITE FEMALES

Figure 3. Black Male Homicide Victims in St. Louis by Age and Gun Involvement (1990-1992 Three-Year Totals)

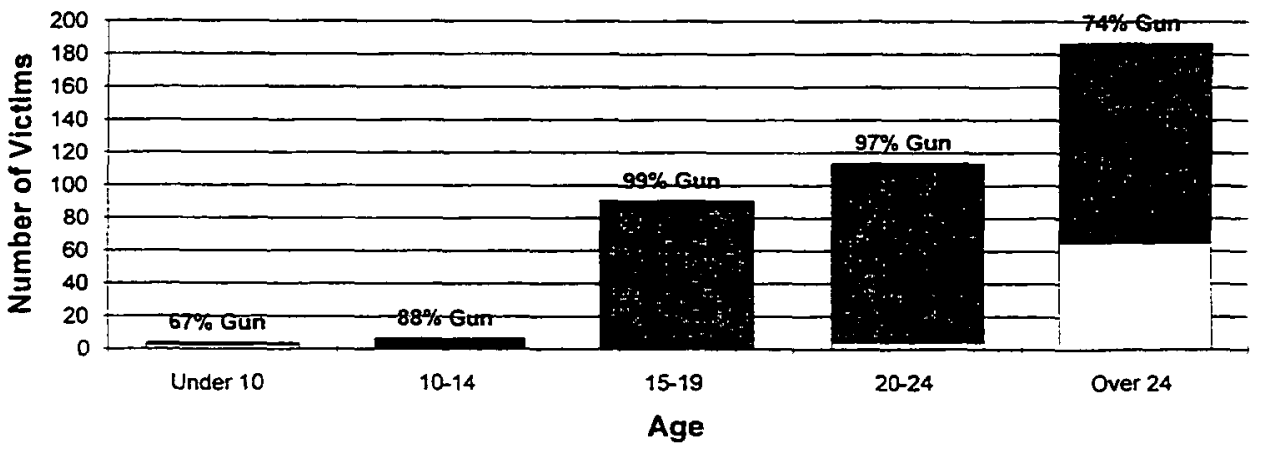


[Vol. 59: No. 1
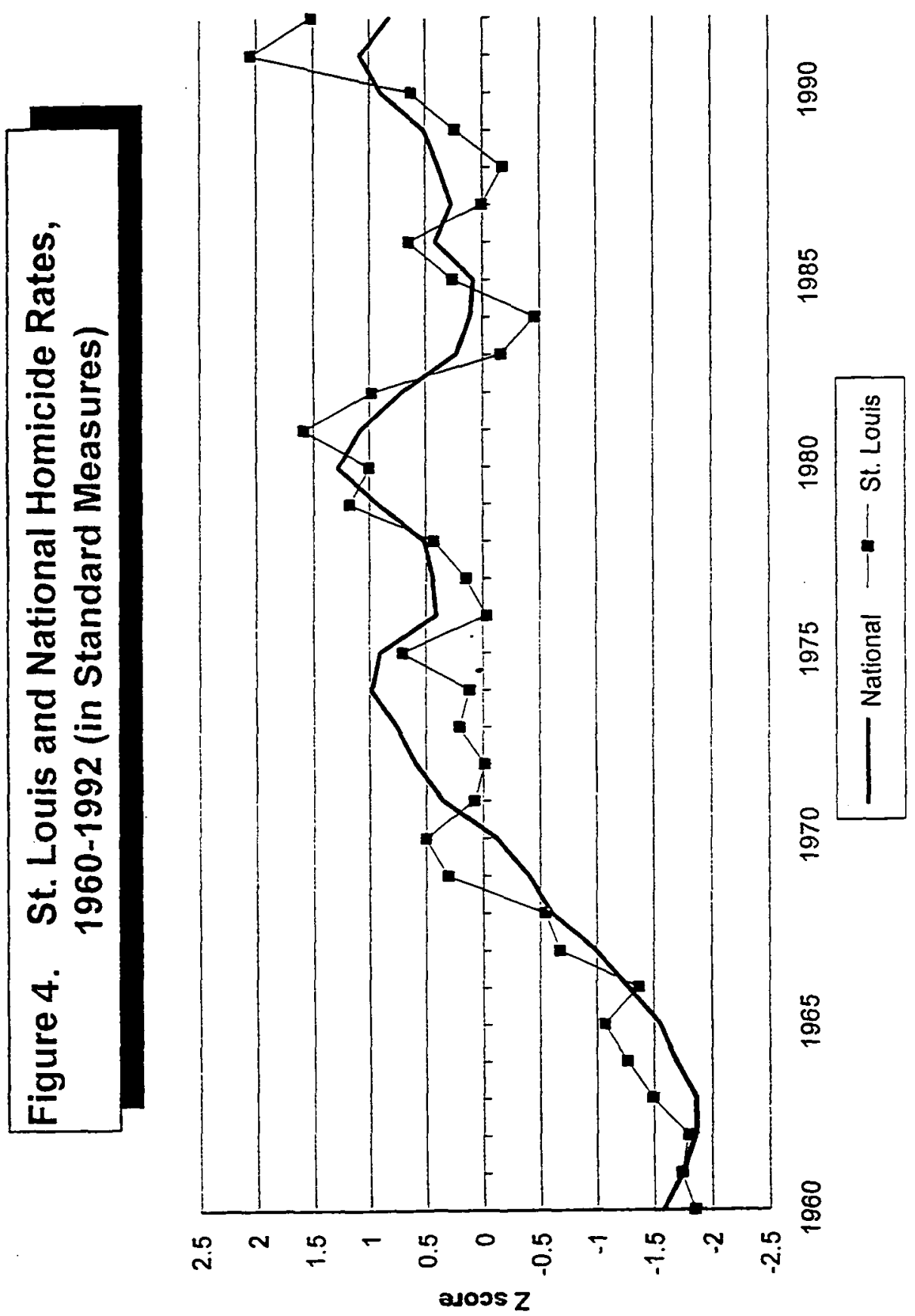

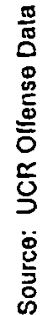


Although levels of homicide and other violent crimes are significantly higher in St. Louis than in many other cities, the demographic patterns of risk demonstrated by the data presented here are quite similar to those for the nation as a whole. ${ }^{4}$ In addition, as revealed in Figure 4, changes in St. Louis's homicide rates over the past thirty years appear to correspond closely with changing national rates. ${ }^{5}$ While these similarities should not be overstated, nor necessarily held to apply to other types of crimes, they do provide some basis for believing that programs which prove effective in St. Louis would be promising candidates for implementation and evaluation elsewhere.

III

\section{A LoOK at St. Louis's Firearm SUPPRESSION PROGRAM}

In recent years, attempts to reduce firearm access and violence have been effected through two different means, one consisting of legislative changes and the other of law-enforcement initiatives.

One legislative change, the Brady Bill, ${ }^{6}$ passed by Congress in 1993, appears to have had some effect on firearm access and weapon-carrying. While the overall effect of the Brady Bill is not yet known, a recent study released by Handgun Control Incorporated, an organization that presses for legal reforms to reduce firearm-related deaths and injuries, indicated that as many as 45,000 applications were rejected during the first year following the bill's enactment. This represents between $2 \%$ and $3.5 \%$ of all background checks required by the Brady Bill. ${ }^{7}$ One study reports reductions in gun crimes in several cities after the enactment of sentence enhancement laws for crimes committed with guns. ${ }^{8}$ These results demonstrate that legislative policies can affect the levels of gun possession and violence in the communities in which they operate.

Police-initiated efforts to curb firearm violence are more varied and plentiful than legislative efforts. They range from the use of metal detectors to identify concealed weapons, to carefully limited, proactive police patrols that attempt to seize large numbers of guns in high-risk areas. ${ }^{9}$ The National Institute of Justice recently examined such a program in Kansas City and found that the

4. See generally MichaEl A. JoNes \& BARRY KRISBERG, IMAGES AND REALITY: JUVENILE CRIME, YOUTh VIOLENCE, AND PUBliC POLICY (1994); HOWARD N. SNYDER \& MELISSA SiCKMUND, JUVENILE OFFENDERS AND VICTIMS: A FOCUS ON VIOLENCE (1995); Alfred Blumstein, Youth Violence, Guns and the Illicit-Drug Industry, 86 J. CRIM. L. \& CRIMINOLOGY 16-36 (1995).

5. Richard Rosenfeld et al., Different Levels, Common Causes: St. Louis Homicide Rates in National Perspective, in QUESTIONS AND ANSWERS IN LETHAL AND NON-LETHAL VIOLENCE (Carolyn R. Block \& Richard L. Block eds., 1993). The series are expressed in units of standard deviation from their respective means to remove scale differences.

6. This bill was passed as the Handgun Violence Protection Act, 18 U.S.C. $\$ \S 921-23$ (1993). The law imposes a waiting period and background check for handgun purchases.

7. Fox Butterfield, Handgun Law Deters Felons, Studies Show, N.Y. TIMES, Mar. 12, 1995, at 13A.

8. See Colin Loftin et al., Evaluating Effects of Changes in Gun Laws, 9 AM. J. PREVENTATIVE MED. 39 (1993).

9. Fox Butterfield, Justice Department Awarding Grants to Develop Gun Detectors, N.Y. TIMES, Mar. 10, 1995, at 22A. 
number of gun seizures was significantly higher, and the number of gun crimes significantly lower in the experimental neighborhood than in a similar control area where the proactive patrol had not been deployed. ${ }^{10}$ As with studies of sentence enhancement laws, these results suggest that such programs can have an impact on both firearm availability and the levels of violent crimes.

The Firearm Suppression Program in St. Louis is another intriguing example of a police-oriented intervention, albeit with significant community involvement, that merits comprehensive and systematic assessment. The FSP is operated by St. Louis's Mobile Reserve Unit, a police squad that responds to pockets of crime and violence throughout the city. The search of a home under the FSP can be initiated by citizen requests for police service, reports from other police units, or by information gained from other investigations. Once the Unit receives a report, two officers visit the residence in question, speak with an adult resident, and request permission to search the home for illegal weapons.

An innovative feature of the program is its use of a "Consent to Search and Seize" form to secure legal access to the residence. ${ }^{11}$ Officers inform the adult resident that the purpose of the program is to confiscate illegal firearms, particularly those belonging to juveniles, without seeking criminal prosecution. The resident is informed that she will not be charged with the illegal possession of a firearm if she signs the consent form.

Perhaps surprisingly, the FSP has generated little criticism from those persons who it most immediately affects: those citizens who are confronted by police officers seeking consent to search their homes. In fact, anecdotal evidence suggests that the program has strong support among adults in neighborhoods with high levels of gun violence. For example, one parent offered to sign multiple pre-dated forms so that the police could return at any time; another wanted to give the police a key to her house to allow them to search while she was at work. Officers involved with the FSP attribute its success to its "low-key approach." "We don't go in like storm troopers," explained one officer. "We realize this concept makes people like the ACLU leery, so we want to avoid complaints. Using a soft approach is why the program has worked. We don't intimidate anyone."12

The FSP has, in fact, attracted criticism from representatives of the local ACLU, who question the possibility of receiving "real" consent to search from someone standing face-to-face with two police officers. ${ }^{13}$ Other critics have charged that the program uses warrantless searches as part of a general firearms confiscation effort that deprives citizens of the right to protect themselves against crime. ${ }^{14}$ Although the police have vigorously denied such claims, the issues raised by the critics are not without merit. The mere request by the

10. See Lawrence W. Sherman et al., The Kansas City Gun EXPERIMENT (1995).

11. See the Appendix, infra page 220, for a copy of this form.

12. Bryan, supra note 1 .

13. Id.

14. $I d$. 
police for consent to search a home may contain, in the words of one FSP critic, a "built-in intimidation factor." 15

Another criticism has been that confiscating guns from juveniles' homes increases the risk that they will become victims of crime. The truth of this proposition, however, remains in doubt, as the issue may have more to do with subjective perceptions of risk than with the "objective" or "true" relationship between firearm possession and personal security. ${ }^{16}$ Regardless, if a juvenile subjectively perceives that his security would be threatened by the loss of his gun, he would be likely to re-arm himself. It remains to be determined, however, whether the economic burden of re-arming is high enough to offset the perception, however mistaken, that owning a gun enhances personal security.

The FSP demonstrates the commitment of local police to problem-oriented policing, a policing strategy that addresses the problems underlying specific crime incidents and citizen requests for police services. The program was developed as a response to problems identified by citizens. By drawing citizens into the process of identifying and confiscating illegal firearms, officers rely on community input and assistance, a central tenet of problem-oriented approaches. $^{17}$

The FSP can also be viewed as an interesting variation of an "aggressive order maintenance" policing strategy. ${ }^{18}$ By agreeing not to arrest adults, the police are free to focus their resources on juveniles. The intent of the program is to send a clear message that juvenile firearm possession will be tolerated neither by the police nor by the community because it puts individuals at risk and threatens the public. The success of the effort largely depends on the quality of the interactions between community members and law enforcement officers.

According to officers in the Mobile Reserve Unit, the program's success will depend on their scrupulous adherence to-the promise not to arrest the consenting adult. Several officers have reported that they are willing to "bite on" (ignore) evidence of all but the most serious crimes in return for access to homes of juveniles with firearms. This reflects the officers' view that the community is better served by removing guns from kids' hands than by using evidence discovered in the search as a basis for making an arrest.

15. Id.

16. See Gary KLeCK, Point Blank: Guns and Violence IN AMERICA (1991); Arthur L. Kellerman et al., Gun Ownership as a Risk Factor for Homicide in the Home, 329 NEW ENG. J. MED. 1084 (1993) (suggesting that gun ownership creates a risk of homicide greater than any security it might provide); Arthur L. Kellerman \& Donald T. Reay, Protection or Peril? An Analysis of Firearm Related Deaths in the Home, 314 NEW ENG. J. MED. 1557 (1986) (suggesting that maintaining a firearm in the home does not increase security, but rather poses a danger).

17. See HeRman GoldSTEIN, THE NEW POLICING: CONFRONTING COMPLEXITY (1993); HERMAN Goldstein, PRoblem-ORIENTED POLICING (1990).

18. For a discussion of an aggressive order maintenance policing strategy, see George L. Kelling, Acquiring a Taste for Order: The Community and the Police, 33 CRIME \& DELINQ. 90 (1987). 
These attitudes can be sustained only by a distinctive organizational culture that emphasizes strong leadership and sub-unit autonomy to help insulate officers from the traditional norms and procedures of "real police work" (such as making arrests, investigating crimes, and pursuing offenders). ${ }^{19}$ Even in departments that encourage problem-solving policing strategies, support for a program like the FSP may be limited. Few police officials consider the reduction of juvenile firearm possession to be a top priority for local law enforcement. In fact, some do not consider such activity to be a component of "law enforcement" at all, while many who do view it as an important and appropriate objective favor a more traditional approach.

For example, some senior officers in St. Louis prefer search warrants because they provide broader access to suspects and their possessions, and because they can be used to remove suspects-not just their weapons-from the streets. These officers generally view the FSP as a "community relations" exercise that has little impact on crime. They also share some of the civil libertarians' concerns regarding the constitutionality of warrantless searches.

As a federalist system, the United States benefits from the authority of the states and localities to experiment with programs addressing problems and issues that plague other areas of the nation. To benefit fully from this system, it is imperative to evaluate these experiments to determine whether they are successful and whether they can be implemented in other jurisdictions. Because youth gun violence is a major problem plaguing much of the nation, innovative programs like the FSP should be evaluated and, if found to be successful, replicated.

\section{IV \\ HOW MANY GUNS?}

A preliminary question that must be answered before assessing the probable effectiveness of programs like the St. Louis FSP is the prevalence of firearm possession and use among juveniles. Judging the importance, feasibility, and impact of firearm suppression efforts heavily depends upon accurate information regarding the number of juveniles who have guns or have access to guns, how and why they acquire them, and what they do with them. However, representative information of this type does not exist. Due to low clearance rates for crimes other than homicide, and the fact that arrest records reflect only the most serious criminal misuse of firearms, arrest data substantially underestimate the level of firearm use by juveniles. General population surveys err in the opposite direction. They indicate that roughly one-half of all households contain firearms, but reveal little about the possession and use of guns specifically by

19. The notion of "real police work" is discussed in John Van Maanen, Kinsmen in Repose: Occupational Perspectives of Patrolmen, in THE POLICE AND SOCIETY: TOUCHSTONE READINGS 225 (Victor E. Kappeler ed., 1995). 
adolescents or by inner-city youth at high risk for violence. ${ }^{20}$ Recent surveys of incarcerated youth and urban high school students provide more useful information, but how far these results can be generalized is unknown. ${ }^{21}$

Systematic evidence on the availability and use of firearms among St. Louis adolescents is unavailable. Nonetheless, results from Drug Use Forecasting ("DUF") surveys conducted in the local juvenile detention facility can provide a rough indication. During the winter and spring of 1995, 128 male detainees between the ages of twelve and sixteen were interviewed about their experiences with firearms. ${ }^{22}$ The data presented in Table 3 show substantial levels of firearm access, use, and criminal involvement on the part of the St. Louis juvenile detainees.

\section{TABLE 3}

Firearm Possession and Use by St. Louis
Juvenile Detainees Ages 12-16 (N=128)
Ever owned or possessed a gun

Among gun owners:

Owned or possessed in last 30 days $\quad 53.2 \%$

Carry a gun

Always

$23.5 \%$

Sometimes

$19.1 \%$

Never

$57.3 \%$

Used a gun in a crime

$26.2 \%$

Stolen a gun

$29.4 \%$

Method of acquiring most recent handgun

Theft

$12.3 \%$

Borrowed

$9.2 \%$

Trade

$18.5 \%$

Paid cash

$46.1 \%$

Gift

$7.7 \%$

Other

$6.2 \%$

Source: Drug Use Forecasting gun addendum survey, 1995

20. See KLECK, supra note 16, for estimates of firearm ownership in the general population. Results from the 1994 General Social Survey ("GSS") indicate that $41 \%$ of American adults own one or more firearms. Firearm prevalence drops to $29 \%$ for metropolitan areas with more than 250,000 residents. The calculations are based on the MicroCase Analysis System program and the GSS data file.

21. See, e.g. JOSEPH F. SHELEY \& JAMES D. WRIGHT, IN THE LINE OF FIRE: YOUTH, GUNS, AND VIOLENCE IN URBAN AMERICA (1995) (surveying youths in California, Illinois, Louisiana, and New Jersey); Charles M. Callahan \& Frederick P. Rivara, Urban High School Youth and Handguns: A School-Based Survey, 267 JAMA 3038 (1992) (determining the prevalence of handgun ownership among urban school youth and how it relates to socioeconomic status, ethnicity, and deviant behavior).

22. Participation rates in the DUF surveys were high with over $90 \%$ agreeing to be interviewed. A few 10- and 11-year-olds were also interviewed. However, due to their small numbers and limited experience with firearms, they were omitted from the results reported here. For a description of DUF sampling and interviewing procedures, see NATIONAL INSTITUTE OF JUSTICE, DRUG USE FORECASTING: 1994 ANNUAL REPORT ON ADULT AND JUVENILE ARRESTEES: A PROGRAM OF THE NATIONAL INSTITUTE OF JUSTICE 10 (1995); see also SCOTT DECKER ET AL., ARRESTEES AND GUNS: MONITORING THE ILLEGAL FIREARMS MARKET (1996) (summarizing the results of firearm surveys conducted in eleven DUF sites during 1995). 
The findings from the survey are as follows: More than one-half of the juvenile respondents in the St. Louis DUF survey have owned or possessed a gun. Of these respondents, one-half had possessed a firearm during the thirty days prior to the interview; roughly one-quarter always carry a gun; one-quarter have used one in the perpetration of a crime; twenty-nine percent have stolen a gun; and twelve percent had stolen their most recently acquired gun, while forty-six percent had paid cash for theirs, and eighteen percent had traded something for it. Additionally, a large majority of respondents had at some point been shot at, or threatened with a gun, and seventy-nine percent listed "protection/self-defense" as the most important reason for having a gun. ${ }^{23}$

These results clearly demonstrate that the juvenile detainees surveyed in St. Louis face a high risk of firearm violence, but it remains to be seen whether these results are representative of the adolescent population in general. While complete information is lacking, data are available that permit rough estimates for a larger population of adolescents. Because all of the juveniles interviewed in the St. Louis DUF surveys were males and nearly all were African-American, our estimates are necessarily restricted to this subgroup. Above, we documented the elevated risk of firearm violence experienced by young African-American males. $^{24}$

It seems obvious that the levels of risk found among juveniles interviewed in a detention facility would be greater than in the general population of young African-American males. Adolescents who are charged with an offense and are referred to the juvenile court, however, should be more similar to those who end up spending time in the detention facility. A sizable number of young black males is referred to the juvenile court each year. In 1994, the most recent year for which data are available, 6,674 referrals were made to the court for felonies, misdemeanors, and ordinance violations. ${ }^{25}$ Assuming that twenty-five percent of these referrals were repeat offenders, 5,005 juveniles were referred to the court in $1994 .^{26}$ We estimate that seventy-eight percent of this population, or 3,904 juveniles, were African-American males. ${ }^{27}$ The 1990 census counted 7,840 black males between twelve and sixteen years old in St. Louis. Based on these figures, in 1994 approximately one-half of the population of these black males $(3,904 / 7,840)$ were referred to the juvenile court on a felony, misdemeanor, or ordinance violation charge.

23. See DECKER ET AL., supra note 22, tbls. 9.4, 9.9 \& 9.10.

24. Supra Parts I, II, figs. 1a-4, tbls, 1 \& 2 .

25. These figures exclude referrals for status offenses and child abuse-neglect cases. The juvenile court data reported in this section are from CITY OF ST. LOUIS FAMILY COURT, TWENTY-SECOND JUDICIAL CIRCUIT OF MISSOURI, REPORT TO THE COMMUNITY (1995) [hereinafter FAMILY COURT].

26. The conventional deflator used to convert the number of arrests to the number of (different) persons arrested in a year is $25 \%$. Applying a larger deflator will reduce the prevalence estimates reported in the text. The sex and race composition of court referrals is not reported in the published juvenile court statistics.

27. Our estimate that $78 \%$ of referrals are black males is based on data for juveniles detained during 1994. See FAMILY COURT, supra note 25 at 8 , tbl. 9. 
Although large, this estimate is consistent with recent reports indicating the fraction of the young, black male population under the supervision of the judicial or correctional system at any given time in selected cities and in the nation as a whole. ${ }^{28}$ When using this figure as the basis for deriving population prevalence estimates of firearm risk, we conclude that, among twelve- to sixteenyear-old African-American males in St. Louis, twenty-six percent have owned or possessed a firearm in their life time; fourteen percent have possessed a firearm during the previous month; six percent always carry a gun; seven percent have used a gun to commit a crime; and eight percent have stolen a gun.

Although subject to error ${ }^{29}$ these estimates are very close to those reported in the literature from surveys of urban adolescents. ${ }^{30}$ The estimates indicate that a large number of adolescents in St. Louis are at risk for firearm misuse and violence.

This high degree of gun possession and misuse suggests that another important issue in the evaluation of gun seizure programs is whether these programs take a sufficient number of guns off the streets to have a measurable impact on the overall level of gun violence in a community. Based on information provided by program officials, FSP officers seized 402 firearms in 1994, the program's first year of operation-just over ten percent of the 3,964 firearms confiscated by or turned in to the police that year. Although this figure appears low, one interpretation is that the present size of the FSP is not sufficient to achieve impressive reductions in illegal firearm possession or use. However, gun seizure programs may have deterrent effects that extend beyond the immediate disruption in the supply of firearms that they are able to achieve. Additionally, the FSP has certain advantages over more traditional methods of gun confiscation. While most guns acquired by the police are confiscated after the commission of a crime, the FSP, as a proactive community policing program, removes illegal firearms from circulation before a crime is committed or an arrest made. Furthermore, the FSP acquires guns from youth who are at higherthan-average risk for criminal involvement and victimization.

Moreover, recall that the FSP and programs like it are not designed to reduce the number of firearms in the total population or even among all persons at risk for violence. Rather, these programs are aimed at the teenage and young-adult segments of the population, those who display high rates of

28. See, e.g., Marc Mauer, Young Black Men and the CRiminal Justice System: A Growing National Problem (1990); Jerome G. Miller, Hobbling a Generation: Young AFRICAN AMERICAN MALES IN WASHINGTON, D.C.'S CRIMINAL JUSTICE SYSTEM (1992).

29. The errors are to some degree counter-balancing. For example, juveniles held in the detention facility are likely to possess and use guns at higher levels than those who have been referred to the court but are not detained. On the other hand, not all juveniles who possess and use guns come to the attention of the court in a given year. Using the behavior of the detainees to characterize all juveniles who are referred to the court will inflate estimates of gun possession and use. Restricting attention to only those juveniles who are referred to the court will deflate these estimates.

30. See, e.g., SHELEY \& WRIGHT, supra note 21 , at $42-43$ (reporting that $30 \%$ of their sample of male, inner-city students had owned a gun and that $4 \%$ always carry a gun). 
victimization and use, but whose actual numbers are relatively small. Based on arrest data for the early 1990s, an estimated twenty percent of persons arrested for gun crimes in St. Louis are under the age of eighteen. Assuming that guns are confiscated from these youthful suspects at the same rate as that for adults, as many as one-half of the firearms taken from juveniles by the police come through the FSP. The number of guns seized in the FSP looks considerably more promising when viewed as a fraction of all guns confiscated from juveniles.

A combination of factors make the FSP an attractive candidate for evaluation: its small size, well-defined procedures, innovative and preventive design, growing national popularity, and narrow focus on adolescents at risk for violence. However, it must be emphasized that the ability to positively link the FSP to changes in firearm possession, personal security, and community safety depends on the willingness of participants to report accurately their perceptions and behaviors related to gun acquisition and use. The high rate of compliance by adults, and the apparent community support for the program, though reassuring, are unlikely to translate into a similar level of cooperation and support by the younger participants. In evaluating such programs, it is essential to counter this problem by including qualitative field researchers who have extensive experience locating and interviewing adolescents at high risk for violence in inner-city communities.

\section{$\mathrm{V}$ \\ EVALUATION Plan}

As this discussion suggests, the criticisms leveled against the FSP provide important starting points for evaluation. A complete evaluation should contain both a detailed process evaluation focusing on the FSP's procedures and purposes, and an equally rigorous, though perhaps more limited, outcome evaluation, examining the program's effects on youth firearm possession, personal security, and community safety.

\section{A. Process Evaluation}

Process evaluation is intended to identity the attributes of individuals, program components, and community characteristics associated with (1) high levels of citizen compliance with police requests to search for and seize firearms, (2) a high ratio of consensual compliance to coerced compliance, and (3) a high ratio of firearms confiscated to searches performed. In short, the manifest purpose of the FSP is to seize the greatest number of illegal firearms using the least amount of coercion. Unfortunately, because the goals and means are likely to be somewhat inconsistent, some trade-offs will have to be made.

For example, the level of compliance with the FSP requests to search is extremely high; Mobile Reserve officers report that more than ninety percent of citizens sign the consent form. It is possible that this high rate of compliance results from an unacceptably high level of coercion by officers or from the citizens' ignorance of their right to refuse permission to search. This example 
suggests a strategy for a process evaluation that measures program performance with respect to the program's three goals. By examining what effects the emphasis of one goal has on the others, a successful evaluation can lead to a determination of the optimal balancing of goals.

Some criticisms of FSP, while important, are beyond the scope of the kind of research described here. Perhaps the most important example is the strict legal question of whether voluntary consent is possible in such a program. The legal requirements for free and informed consent in the FSP police-citizen encounters, as noted, remain in some dispute. However, analysis of the problem of consent is not restricted to the domain of formal legal inquiry. Some, if not all, of the requirements for legal consent presuppose specific fact conditions that are open to evaluation. An obvious example is whether the police inform citizens that they will not be penalized if they refuse to grant written permission for the police to search their homes.

A more complicated issue involves how the police acquire information about a juvenile's possession of a firearm, and how they obtain consent to search his home. Consider, for example, a situation in which the police are called by a mother and asked to search her home for guns. This is not an uncommon occurrence, according to St. Louis Mobile Reserve officers. It clearly defines one extreme on a continuum of voluntary consent. At the other extreme is the plainly coercive use of "consent" to substitute for a warrant. This is the situation that worries some FSP critics who imagine the police threatening: "If you don't let us search your house, we'll get a warrant and, if we find a gun, we'll arrest you." Suppose, however, the police appear at a mother's door at midnight, wake her up, and announce: "We think your son has a firearm. We want to enter your home to search for it, and if you sign a form we won't arrest him or you." Here, the police use a carrot to induce consent-rather than a threat of harm-yet the outcome is functionally the same: The police are able to search a house without a warrant. ${ }^{31}$

Evaluation research cannot resolve the issue of whether the voluntariness of the consent is markedly different in the two situations. However, the social processes in which consent is requested, discussed, and granted or denied is open to empirical investigation. An effective evaluation would produce a comprehensive account of this process through interviews with officers and citizens, and observations of the interactions between these two groups. This account is intended to reveal characteristics - of officers, of citizens, and of their "porch

31. We are indebted to St. Louis University law professor Roger Goldman for calling our attention to these issues. Professor Goldman also suggests that the legal status of the FSP consent procedures would depend on whether they were used by individual officers as a discretionary response to a specific fact situation or were part of a formal departmental policy. In the latter case, legal questions could turn on whether the policy is narrow in scope and restricted to specially trained officers in a specific unit, as in the St. Louis case, or whether it covers a broad class of criminal events and can be invoked by any beat patrol officer. Letter from Professor Roger Goldman, St. Louis University, to Professor Richard Rosenfeld, University of Missouri-St. Louis (Aug. 24, 1995 \& Oct. 2, 1995) (on file with Professor Rosenfeld). 
step" encounters-associated with the decision to grant or withhold consent. The descriptive material also should be examined for evidence of officers' coercion, for citizens' understanding of the program's purposes, and for citizens' knowledge of their right to refuse permission to search. In each case where consent is given, it is important to determine empirically the degree to which it is given "freely."

In summary, a comprehensive process evaluation should produce information that is highly relevant to the debate over the requirements of warrantless searches under varying conditions, even if it cannot assess the legal status of such searches directly. We suggest the following questions as points of departure for process evaluations of the FSP and related programs:

What are the various sources of information police officers use to decide whether to initiate a consent-to-search contact (for example, informants or other street contacts, information from criminal investigations, complaints from neighbors, requests from parents)?

How reliable is this information? Specifically, what fraction of "tips" from each source results in a request to search a household for a firearm, and what fraction of these searches leads to the confiscation of a weapon?

How does police organizational culture adapt to and integrate a problemoriented approach in the area of firearms control? How is the integrity of the consent-to-search process safeguarded and sustained over time?

On what grounds do officers decide to initiate a voluntary consent-tosearch request instead of securing a warrant to search for illegal firearms? What fraction of voluntary searches might have satisfied the requirements for a warrant? How do these cases differ from those in which the police have or would have obtained a warrant to search a home for illegal weapons?

What is the nature of the police-citizen interaction in which FSP officers attempt to initiate a search? How do police obtain consent and subsequent cooperation from community members who may be skeptical of police motives? What role does coercion play in this process? How do residents respond to police requests? What types of police behavior are most likely to generate citizen cooperation?

How do juveniles in the home respond to police searches of their possessions? 
To address these questions, qualitative data collection is required in each of three domains. The first involves interviews with and observations of officers at headquarters, carried out over a sufficient period of time to acquire a sense of the unit's organizational culture, as well as to accustom officers to the presence of researchers in their daily activities. It is important to determine how officer behavior consistent with the purposes of problem-oriented programs like the FSP are promoted and sustained, especially when such behavior conflicts with customary law enforcement procedures.

Officials who seek to change a traditional police culture that emphasizes arrest and formal intervention, and promote instead the values associated with the FSP face two difficult tasks. The first is to convince officers of the efficacy of a new "softer" harm-reduction strategy that emphasizes negotiations with citizens. The second is to convince citizens that they will not be penalized for complying with police requests to enter and search their homes for weapons, nor for refusing to cooperate. Such changes in both police and citizen behavior have not been easy to accomplish under the best of circumstances in communityoriented policing programs. ${ }^{32}$ They are undoubtedly even more difficult to sustain in urban inner-city areas that suffer from historically high levels of antipathy between the police and residents, and currently face very high levels of firearm violence.

The second domain of qualitative data collection for a process evaluation of the FSP involves interviews and observations during ride-alongs with officers throughout their shift. The ride-alongs provide the opportunity to observe how the "ideal" behavior promoted by police administrators is actually implemented on the street. Ride-alongs also permit direct observation as to how officers obtain information regarding the possible presence of firearms in the homes of juveniles.

The third and most important data-collection component of the process evaluation entails direct observation of the interaction between officers and community residents when the officers seek permission to search their homes for firearms. Documenting variations across officers, neighborhoods, and community residents in the consent-to-search process permits assessment of the most successful strategies for gaining compliance under different conditions.

\section{B. Outcome Evaluation}

Outcome evaluation combines qualitative and quantitative techniques. For the FSP and similar interventions, this evaluation has three objectives: (1) to determine whether the program results in a net reduction in firearm possession by young people; (2) to determine whether the confiscation of guns threatens

32. See, e.g., Jack R. Greene, Police and Community Relations: Where Have We Been and Where Are We Going?, in CRITICAL ISSUES IN POLICING: CONTEMPORARY READINGS 349 (Roger G. Dunham \& Geoffrey P. Alpert eds., 1989); George L. Kelling, \& Mark H. Moore, The Evolving Strategy of Policing, in THE POLICE AND SOCIETY: TOUCHSTONE READINGS 3 (Victor E. Kappeler ed., 1995). 
their "personal security" (their perceived risk for violence); and (3) to measure the program's influence on the level of community safety.

As for the first objective, a key research issue is whether the FSP confiscation itself results in significant re-arming of program participants. This issue therefore connects with the second objective. In order to effect a net reduction in firearms, there must be minimal levels of re-arming. To explore this connection, juveniles whose homes have been searched by the police should be re-interviewed at periodic intervals regarding their personal security. Juvenile offenders and inner-city adolescents report that the most important reason they carry a firearm is to protect themselves in environments they perceive as hostile and threatening. ${ }^{33}$ It follows that, all else being equal, confiscating the firearm from a juvenile who acquired it for self-protection will reduce his personal security. If diminished security increases the perceived need for a weapon, then a large number of these individuals will be likely to re-arm themselves.

The re-arming of many juveniles is a realistic expectation, but testing this expectation with good estimates of the rate of re-arming will be difficult. Such estimates necessarily involve many uncertainties. Even when based on generous assumptions about the number of follow-up interviews needed for a minimally reliable measurement of gun re-acquisitions, and about the proportion of juveniles willing to participate in these interviews, existing data from the St. Louis program do not yield precise conclusions about the impact of gun seizures on adolescent firearm possession. Let us assume, for example, that a minimum of twenty follow-up interviews is necessary to estimate reliably the fraction of gun confiscations that results in the acquisition of replacement guns within a three-month time interval. As noted, FSP officers seized 402 firearms in 1994. During the first quarter of 1995,104 guns were seized, a pace comparable to the previous year. FSP officials report finding guns in roughly half of the houses they search, averaging three guns seized per house searched. Based on these figures, FSP officers conduct approximately 130 searches per year in which firearms are found, about thirty to thirty-five "successful" searches every three months. ${ }^{34}$ Consequently, nearly two-thirds of all adolescents whose guns had been seized during the previous three months would have to agree to be interviewed in order to estimate reliably the rate of re-arming. This almost certainly over-estimates the proportion of inner-city adolescents who would voluntarily submit to additional inquiry into their gun acquisition behavior. Further, these hypothetical results are based on data averaged over twelve months and, therefore, may provide an inadequate description of a particular observation period.

33. SHELEY \& WRIGHT, supra note 21 , at 67-69.

34. If a half of all searches yield a firearm, and an average of three firearms are seized in a successful search, then based on the 1994 data the police netted 402 firearms from a total of 268 searches conducted during the year $((402 / 3) \times 2)$. On average, then, 65 to 70 searches take place in a three-month period, half of which, about 30 to 35 , result in the seizure of firearms. 
The success of FSP officers in obtaining weapons is highly variable over time, as is the number of residences they are able to search. According to program officials, between five and thirty houses are searched in an average shift. On some nights no guns are found, while on others many are seized, such as one night when nine of the ten searches netted firearms. The most guns recovered in a single search is thirty-six. Given the large variance in the number of searches conducted per day and in the number of firearms confiscated per search-coupled with less than optimal expected response rates for the follow-up interviews-a long observation period would be necessary to assess reliably the FSP's impact on juvenile gun possession.

Finally, an outcome evaluation of seizure programs such as the FSP should gauge their general impact on community safety. Areas in which the program is most active, as measured by requests to search homes and by gun confiscations, should observe significant declines in firearm activity compared to those where the program has been less visible. A useful set of empirical indicators is available in St. Louis for measuring variations across space and time in firearm activity and violence. The St. Louis Police Department is nationally known for the quality, detail, and variety of its violent crime statistics. However, nearly all urban police departments maintain comparable information on firearm incidents.

Figure 5 illustrates changes in the levels of two particularly useful indicators of firearm use: the number of shootings and shots fired reported to the police. These indicators show a decline in firearm violence during the early and mid1980 s, and a substantial increase in the late 1980s and early 1990s. Above the bar graphs is a line representing the number of gun homicides committed during the same period. The figure suggests correspondence among the three time series. These data are available at the address level and therefore can be geocoded (classified by exact location of incident) for comparative assessment in areas and time periods in which firearm suppression activity is high and low. As an example, Figure 6 displays the geographical distribution of homicides and shots-fired calls in St. Louis neighborhoods during 1993. One neighborhood is highlighted, and an even smaller hypothetical "target area" circled within, to show the feasibility of monitoring program effectiveness for relatively small geographical areas. By examining changes in gun use indicators in varying time intervals and for different geographical units, investigators should be able to measure the FSP's impact on community safety. 
Figure 5. Reports of Shootings, Shots Fired, and Gun Homicides in St. Louis, 1981-1992

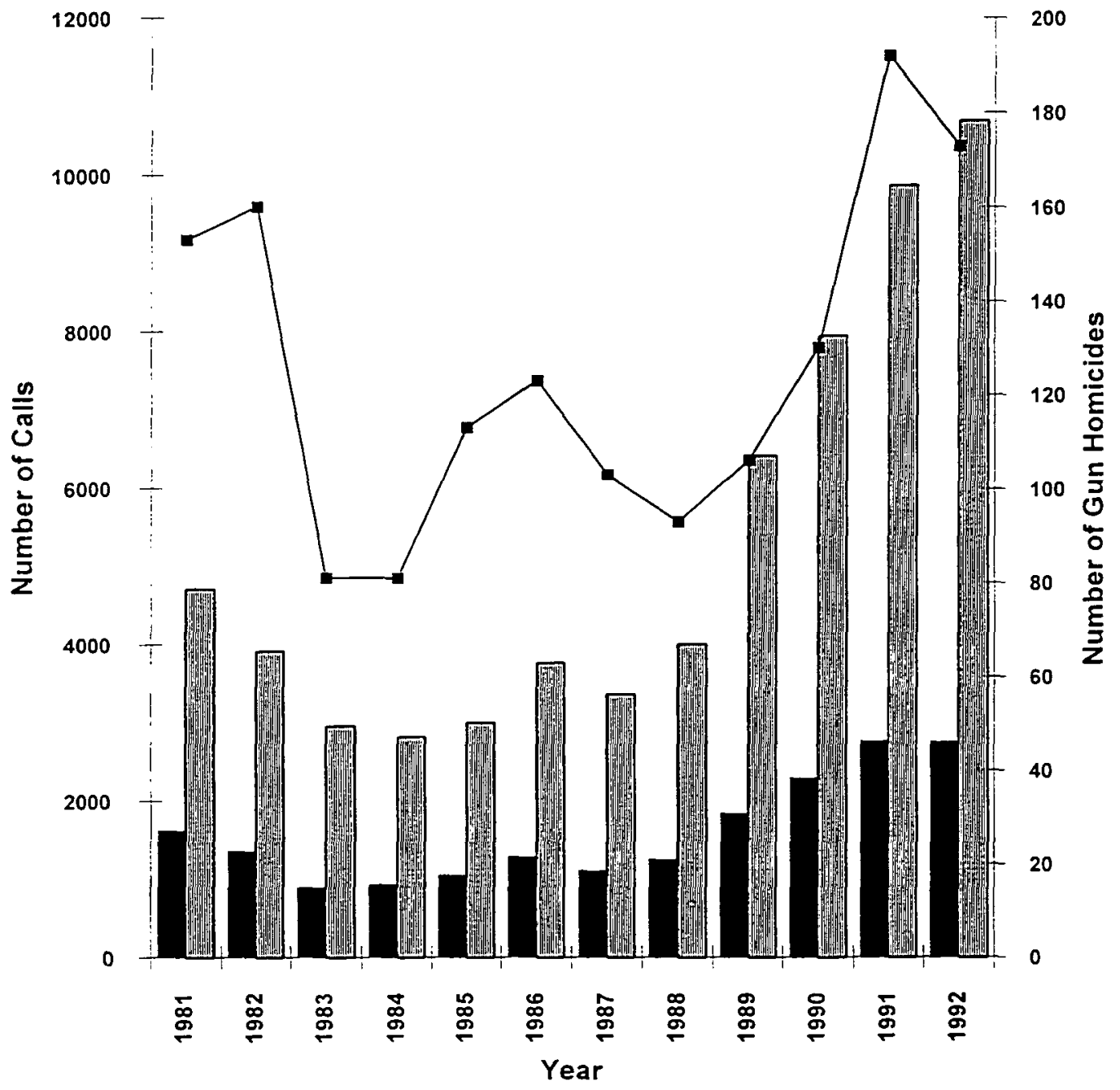




\section{Figure 6. Homicides and Shots Fired Calls in St. Louis, 1993}

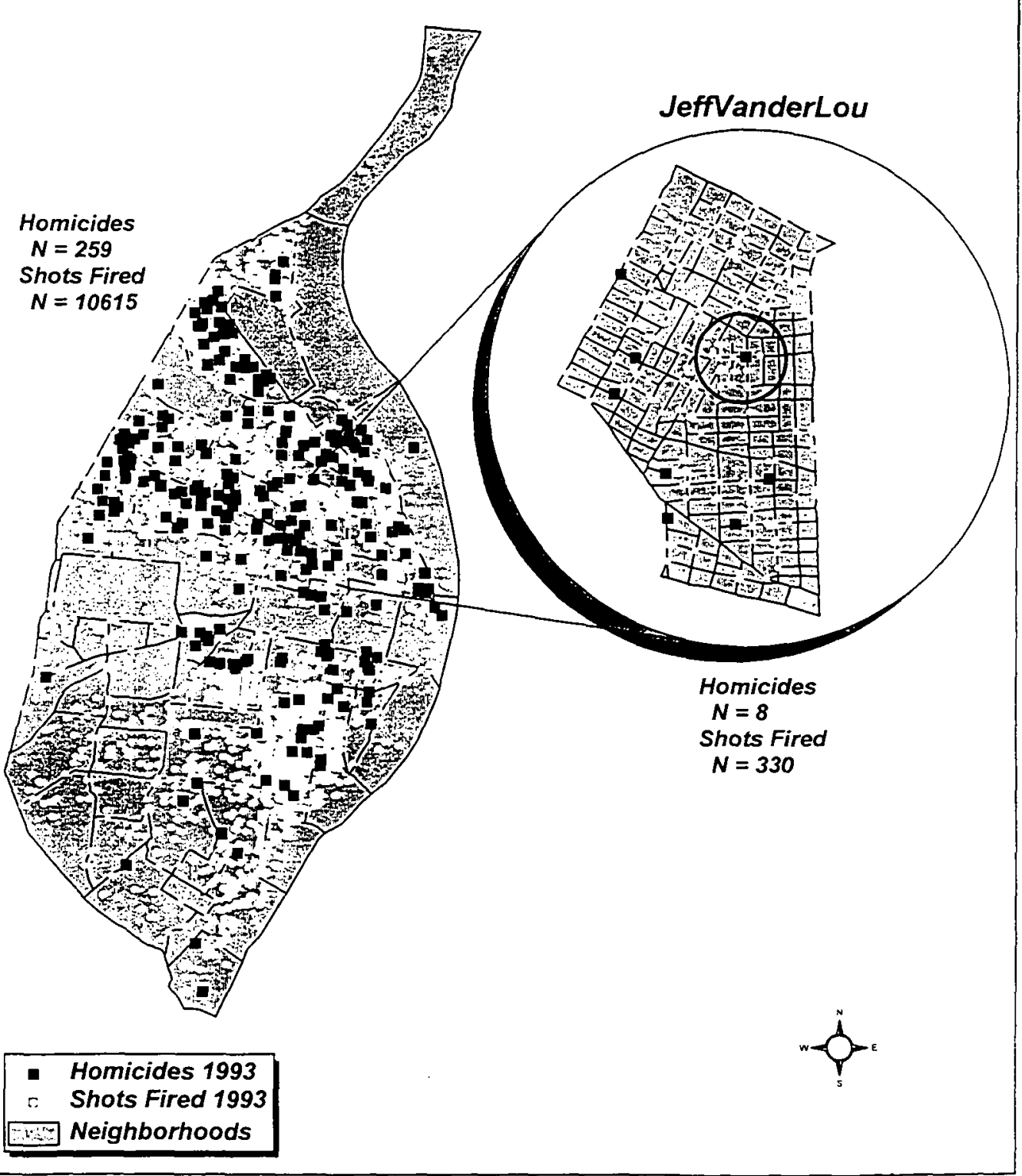




\section{VI \\ CONCLUSION: BRINGING THE KIDS BACK IN}

St. Louis's Firearm Suppression Program shows considerable promise as a problem-solving initiative to address the alarming level of youth firearm violence in the nation's cities. The program's attractive features are its proactive orientation, well-defined mission, location in a special police unit with city-wide jurisdiction, popularity with community residents, and use of consent searches to complement traditional methods of crime control. Although the program has attracted widespread interest and the initial experience has been positive-several hundred guns have been confiscated without complaints from community members-it remains to be determined how long such an effort can be sustained and how effective it is in reducing the risk of firearm violence. Indeed, we do not even know whether the sizable number of guns the program has taken out of the hands of juveniles represents anything more than a temporary arms reduction. A central objective of evaluating programs such as the FSP is to determine how rapidly kids re-arm themselves after the police have taken away their guns.

As we learn about the capability of such programs to reduce juvenile firearm possession and use, we must also probe the programs' effects on broader perceptions, attitudes, and behavior. In evaluating police-citizen partnerships such as the St. Louis FSP, law enforcement officials, parents, and researchers must not lose sight of the adolescents whose privacy is disturbed and whose possessions are searched without a warrant. In many instances, these searches occur without their consent. If little is known with certainty about the effects of search and seizure programs on firearm possession, even less is known about the impact on the "totality of circumstances" that influence an adolescent's sense of personal security and relationships with peers, parents, and the FSP.

A thoughtful critic of the FSP asks a simple but fundamentally important question: How do adolescents react to having their possessions and facilities searched by the police? How many object vehemently, either out of fear that the police might find a gun, or out of anger that they will not? Do some move out of the house, drop out of school, join a gang, retaliate against parents or peers who consent to a search? Although such questions bear partly on the legality of warrantless searches, especially involving older adolescents, ${ }^{35}$ they also alert us to the possibility that firearm seizure programs may aggravate some of the problems they intend to alleviate. The long-range integrity and

35. Roger Goldman points out that the law has traditionally provided ample space, under parens patriae doctrines, for parents to give legal consent for their children. Supra, note 31 . However, recent attention to privacy issues involving adolescents raises interesting questions about the contemporary application of such doctrines to an FSP-type consent procedure. Id. What standards would a court use to gauge the legality, in an example Goldman offers, of a mother's consent to search the possessions of a 19-year-old son who pays her rent, has a separate entrance and lock, and is present during the search and objects? Id. 
effectiveness of the FSP and similar violence-prevention efforts will be undermined if they instead harden pre-existing mistrust and hostility toward the police, reduce respect for law, and increase tensions within families. We do not know whether the FSP has such unintended consequences, but that is precisely because its juvenile participants have been treated as silent partners in this community policing program to disarm urban youth. 


\section{APPENDIX \\ St. Louis Form For CONSENT to SEARCH ANd SEIZE}

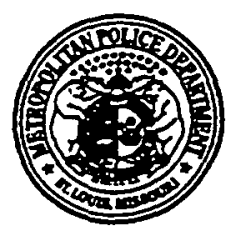

\section{ST. LOUIS METROPOLITAN POLICE DEPARTMENT MOBILE RESERVE SECTION FIREARM SUPPRESSION PROGRAM}

\section{CONSENT TO SEARCH AND SEIZE}

Police Officers of the Mobile Reserve Section are currently engaged in a Firearm Suppression Program. The purpose of this Furearm Suppression Program is to locate and recover ilegal and/or unregistered firearms. As part of this program said otficers agree that should any illegal or unregistered firearms be located in the residence the person authorizing the search of the premises will not be charged with ithegal possession of a firearm.

Having authority to authorize a search of the premises, do hereby grant officers of the St. Louis Metropolitan Police Department permission to search and remove any illegal and/or unregistered firearms.

POUCE OFFICER SIGNATURE

DATE

OF

(Adders)

FIREARMS SEIZED: 